\title{
Tolerância à seca de genótipos de trigo utilizando agentes indutores de estresse no processo de seleção
}

\author{
Larissa Girotto ${ }^{1}$, José Donizeti Alves ${ }^{2}$, Sidnei Deuner ${ }^{*}$, Ana Christina Sagebin Albuquerque ${ }^{4}$, \\ Ana Paula Tomazoni ${ }^{5}$
}

\begin{abstract}
RESUMO
Com o objetivo de selecionar genótipos de trigo tolerantes à seca, por meio da indução de déficit hídrico por diferentes agentes osmóticos, sementes e embriões imaturos de oito genótipos foram submetidos a diferentes gradientes osmóticos e avaliados quanto ao comprimento da parte aérea e da raiz principal e à produção de biomassa total. As sementes foram submetidas aos agentes polietilenoglicol-6000 e manitol, em sete gradientes osmóticos, e avaliadas após dez dias. Os embriões foram cultivados em meio macrobatata, suplementado com PEG 6000, manitol e maltose nas concentrações de 10, 20 e 30\%, além do controle, e avaliados após 30 dias de incubação. O delineamento foi inteiramente casualizado e os dados foram submetidos à análise de regressão, utilizando-se o teste " $t$ ", para comparar os valores de Beta, e análise de variância, com teste de médias pelo teste "t". Houve efeito do estresse hídrico em todos os genótipos testados para as plântulas oriundas de sementes, com interação significativa entre agente e cultivar e efeito negativo maior para PEG 6000. Os genótipos BH 1146 e Ocepar 14 apresentaram maior tolerância à seca, redução média no crescimento, na presença dos agentes estressantes, de 58 e 62\%, respectivamente. Em contraste, o Aliança foi o mais sensível, com redução média de 92\%. Para as plântulas oriundas de embriões imaturos, o genótipo BH 1146 também apresentou relativa tolerância; já o Ocepar 14 e Aliança foram altamente sensíveis. Porém, estes genótipos também apresentaram baixo desempenho no meio sem a presença dos agentes estressantes, podendo o efeito negativo estar condicionado ao cultivo in vitro.
\end{abstract}

Palavras-chave: Triticum aestivum L., déficit hídrico, crescimento.

\section{ABSTRACT}

\section{Drought tolerance of wheat genotypes using stress-inducing agents during selection}

The aim of this study was to select wheat genotypes tolerant to drought by inducing water deficit using different osmotic agents. Seeds and immature embryos of eight wheat genotypes were subjected to different osmotic gradients and evaluated for shoot length, main root and total biomass production. Seeds were subjected to the osmotic agents polyethyleneglycol-6000 and mannitol in seven osmotic gradients and evaluated after 10 days. The embryos were cultured in potato medium supplemented with PEG 6000, mannitol and maltose at the concentrations of $10 \%, 20 \%$ and $30 \%$, plus a control, and evaluated after 30 days of incubation. The experimental design was completely randomized and data submitted to regression analysis using the " $t$ " test to compare the Beta values and analysis

Recebido para publicação em 26/11/2010 e aprovado em 25/11/2011

${ }^{1}$ Bióloga, Mestre. Empresa Brasileira de Pesquisa Agropecuária, Embrapa Soja, Laboratório de Biotecnologia Vegetal, Caixa Postal 231,86001-970, Paraná, Brasil. larissagirotto@yahoo.com.br

${ }^{2}$ Engenheiro-Agrônomo, Doutor. Universidade Federal de Lavras, Setor de Fisiologia Vegetal, Departamento de Biologia, Caixa Postal 3037, 37200-000, Lavras, Minas Gerais, Brasil. jdalves@ufla.br

${ }^{3}$ Engenheiro-Agrônomo, Doutor. Empresa Brasileira de Pesquisa Agropecuária, Embrapa Cerrados, BR 020, km 18, 73310-970, Planaltina, Distrito Federal, Brasil. sdeuner@ yahoo.com.br *Autor para correspondência.

${ }^{4}$ Engenheira-Agrônoma, Mestre. Empresa Brasileira de Pesquisa Agropecuária, Embrapa Trigo, Caixa Postal 451, 99901-970, Passo Fundo, Rio Grande do Sul, Brasil. ana.albuquerque@embrapa.br

${ }^{5}$ Estudante de Graduação em Ciências Biológicas. Universidade de Passo Fundo (UPF), BR 285, São José, 99052-900, Passo Fundo, Rio Grande do Sul, Brasil. ana_tomazoni @ yahoo.com.br

Rev. Ceres, Viçosa, v. 59, n.2, p. 192-199, mar/abr, 2012 
of variance with test of means by " $t$ " test. There was effect of water stress on all genotypes tested for the seedlings originated from seeds, with significant interaction between osmotic agent and genotype and greater negative effect for PEG 6000.

Genotypes BH 1146 and Ocepar 14 showed the highest tolerance to drought and mean reduction in growth, in the presence of stressors, of 58\% and 62\%, respectively. In contrast, the genotype Alliance was the most sensitive with an average reduction in growth of $92 \%$. For seedlings derived from immature embryos, the genotype BH 1146 also showed relative tolerance, but Alliance and Ocepar 14 were highly sensitive. However, these genotypes also showed poor performance in the culture medium without the presence of stressors, thus, the negative effect may be due to the in vitro culture.

Key words: Triticum aestivum L., water deficit, growth.

\section{INTRODUÇAO}

O trigo (Triticum aestivum L.) é um dos principais alimentos da humanidade, ocupando aproximadamente $20 \%$ da área cultivada no mundo, com uma produção em torno de 673 milhões de toneladas/ano (Abitrigo, 2010). No Brasil, sua produção concentra-se no sul e centro-sul do país, tendo como principal produtor o Estado do Paraná. O volume total de trigo colhido na safra 2009/2010 foi de aproximadamente 5,04 milhões de toneladas e o consumo nacional deste cereal é de aproximadamente 10,5 milhões de toneladas, o que tem obrigado o país a importar mais de 5,0 milhões de toneladas anualmente (CONAB, 2010).

Entre os vários fatores limitantes da produção vegetal, o déficit hídrico ocupa os primeiros lugares, pois além de afetar as relações hídricas nas plantas, alterando-lhes o metabolismo, o fenômeno ocorre em grandes extensões de áreas cultiváveis. Estresses abióticos, como a seca, além de reduzirem significativamente o rendimento das lavouras, restringem as latitudes e os solos onde espécies comercialmente importantes poderiam ser cultivadas (Nogueira et al., 2001). Por esta razão, o melhoramento para a tolerância à seca assume grande importância, em programas de melhoramento de plantas para regiões sujeitas ao déficit hídrico em fases críticas do ciclo da cultura.

A produtividade do trigo depende da quantidade de água disponível no solo, sendo que cultivares tolerantes à seca podem utilizar, pelo menos, dois mecanismos distintos para um maior aproveitamento da água, como reduzir a quantidade de água consumida, ou produzir mais grãos, por uma mesma quantidade de água (Fumis \& Pedras, 2002). A água de irrigação é um dos recursos cada vez mais limitantes, daí a necessidade de técnicas e métodos que permitam aumentar a produtividade das culturas a cada unidade de volume de água aplicada (Denadai \& Klar, 1995).

O grande desafio, em programas de melhoramento vegetal para tolerância à seca, é a identificação e a carac- terização de genitores apropriados para regiões historicamente conhecidas como propensas ao déficit hídrico durante as estações de plantio. Neste contexto, um primeiro passo para a obtenção de genótipos tolerantes à seca é a seleção de germoplasma adaptado às condições de estresse, buscando submeter plântulas ou sementes dos diversos genótipos às condições de estresse osmótico in vitro. Dentre as substâncias mais usadas, encontram-se o polietilenoglicol (PEG), o manitol e sais inorgânicos $(\mathrm{NaCl}$, $\mathrm{MgSO}_{4}$ e $\mathrm{KNO}_{3}$ ) (Vazquez, 1995). Paralelamente, podem-se associar marcadores moleculares ao estresse abiótico, caso em que a associação dessas estratégias fisiológicas poderá fornecer, mais precocemente, candidatos identificados como genótipos tolerantes ao estresse hídrico. Esses genótipos serão incorporados nos programas de melhoramento, reduzindo o custo e o tempo para a liberação de novas variedades.

Desta forma, para simular condições de estresse hídrico em laboratório, estudos de germinação têm sido realizados com soluções aquosas de PEG 6000 e manitol, dentre outros. Estes ensaios têm ajudado na identificação de cultivares com elevado nível de resistência a condições de estresse. Em soja, Schuab et al. (2007) verificaram que o teste de germinação sob potencial osmótico de $-0,2 \mathrm{MPa}$, induzido por PEG 6000, apontou diferenças no vigor das sementes, e Silva et al. (2006) indicaram o teste de germinação sob -0,6 MPa como procedimento promissor para a avaliação do potencial fisiológico das sementes dessa espécie. Trabalhos semelhantes foram conduzidos com girassol (Barros \& Rossetto, 2009), algodão (Meneses et al., 2011), milho (Tonin et al., 2000) e arroz (Pirdashti et al., 2003).

Portanto, com esses testes, as empresas produtoras de sementes podem selecionar lotes com desempenho superior, capazes de germinar em condições de estresse ambiental, tal como estiagem na época da semeadura. Assim, o objetivo deste trabalho foi selecionar genótipos de trigo tolerantes à seca, pela indução do déficit hídrico por diferentes agentes osmóticos. 


\section{MATERIAL E MÉTODOS}

O trabalho foi desenvolvido no Laboratório de Biotecnologia Vegetal e no Laboratório de Sementes da Embrapa Trigo, Passo Fundo-RS. Para tanto, oito genótipos de trigo, fornecidos pelo Banco Ativo de Germoplasma de Cereais de Inverno da Embrapa Trigo, agrupados como potencialmente tolerantes, Grupo 1 (Aliança, BH 1146 e Ocepar 14) e susceptíveis à seca, Grupo 2 (BR 18, BRS 207, BRS 208, BRS 210 e BRS 264) foram submetidos a diferentes gradientes osmóticos estabelecidos por meio de agentes indutores de estresse hídrico. As avaliações foram realizadas em plântulas oriundas de sementes e embriões imaturos.

Inicialmente, sementes foram esterilizadas em solução de hipoclorito de sódio $(\mathrm{NaOCl})$ a $50 \%$, por 15 minutos e, em seguida, enxaguadas em água destilada. Cinquenta sementes de cada genótipo foram dispostas sobre uma camada de papel filtro, com auxílio de um plantador automático, acondicionadas em gerbox e submetidas a dois distintos agentes estressantes, que simulam déficit hídrico, o polietilenoglicol (PEG 6000) e o manitol. Foram estabelecidos sete gradientes osmóticos para cada agente estressante nas concentrações de: zero (controle); - 0,$05 ;-0,10 ;-0,20$; 0,$40 ;-0,60$ e -0,80 MPa, aplicando-se um volume de solução ou água de $20 \mathrm{~mL}$ por tratamento. Em seguida, as sementes foram colocadas para germinar em câmara de crescimento, por um período de 10 dias, a uma temperatura média de $22^{\circ} \mathrm{C}$ $\pm 2^{\circ} \mathrm{Ce} 50 \%$ de umidade relativa.

$\mathrm{O}$ experimento foi conduzido em um delineamento inteiramente casualizado, sendo utilizadas três repetições de 50 sementes para cada genótipo, por agente indutor de estresse e por gradiente osmótico. Após 10 dias em câmara de crescimento, o comprimento relativo da parte aérea, da raiz principal e a massa fresca total de 20 plântulas de cada genótipo, por tratamento, escolhidas aleatoriamente, foram determinados com o auxílio de régua milimetrada e balança analítica. Os resultados foram submetidos à análise de regressão, para determinar se houve efeito estressante das doses dos agentes utilizados sobre os diferentes genótipos e o tipo de curva de resposta representativa dos resultados obtidos (linear e quadrática), pelo software SAS 9.1.3. O teste F foi utilizado para definir a significância do modelo e o teste " $t$ " para comparar os valores de Beta.

$\mathrm{Na}$ segunda etapa do experimento, foi avaliado o efeito dos agentes indutores de estresse hídrico, sobre características de crescimento em plântulas dos oito genótipos de trigo, oriundas de embriões imaturos, que foram coletados aos 10 e 20 dias, após a antese, e cultivados in vitro. Depois de colhidas, as espigas de trigo foram transferidas para laboratório e suas sementes removidas cuidadosamente, com auxílio de uma pinça e, então, levadas para desinfestação superficial em câmara de fluxo laminar, onde permaneceram imersas em solução de $\mathrm{NaOCl}$ a $50 \%$, por 15 minutos. Ao final deste período, foram lavadas em água Milli-Q e seus embriões retirados, com o auxílio de pinças e bisturis esterilizados, e transferidos para tubos de ensaio fechados com tampas plásticas translúcidas e selados com filme de PVC transparente, onde foram submetidos aos distintos tratamentos, simulando os níveis de estresse.

Os embriões imaturos foram cultivados em meio de cultura modificado "macrobatata", segundo Chuang et al. (1981), sendo, seus componentes e quantidades para 1 litro, compostos por extrato de batata aquoso $5 \%, \mathrm{Fe}-$ EDTA $\left(10^{-4} \mathrm{~mol} \mathrm{~L}^{-1}\right)$, vitaminas $\left(1 \mathrm{mg} \mathrm{L}^{-1}\right)$, ácido indol-3acético $\left(10^{-6} \mathrm{~mol} \mathrm{~L}^{-1}\right)$, sacarose $\left(30 \mathrm{~g} \mathrm{~L}^{-1}\right)$ e agar $\left(7 \mathrm{~g} \mathrm{~L}^{-1}\right)$, com $\mathrm{pH}$ corrigido para 5,8. Para induzir o estresse hídrico nos embriões, o meio foi suplementado com três agentes estressantes em diferentes concentrações, PEG 6000 a $10 \%$ $(-0,05 \mathrm{MPa}) ; 20 \%(-0,07 \mathrm{MPa})$ e $30 \%(-0,12 \mathrm{MPa})$, manitol a $10 \%(-1,36 \mathrm{MPa}) ; 20 \%(-2,72 \mathrm{MPa})$ e $30 \%(-4,09 \mathrm{MPa})$ e maltose a $10 \%(-0,69 \mathrm{MPa}) ; 20 \%(-1,39 \mathrm{MPa})$ e $30 \%(-2,06$ $\mathrm{MPa})$, além do controle sem a presença dos agentes estressantes, totalizando 10 tratamentos para cada genótipo com meios de cultura distintos.

Em cada tubo de ensaio, foi acondicionado um embrião imaturo, e, esses tubos foram mantidos em câmara de crescimento, no escuro, por 96 horas, a $20 \pm 2^{\circ} \mathrm{C}$. Após esse período, os tubos foram submetidos à irradiância de $36 \mu \mathrm{mol} \mathrm{m} \mathrm{s}^{-2}$, fotoperíodo de 12 horas e temperatura de $20 \pm 2^{\circ} \mathrm{C}$ e, após 30 dias de incubação, foram determinados o comprimento da parte aérea, o da raiz principal, a massa de matéria fresca total e a massa de matéria seca total, após transferência para estufa a $65^{\circ} \mathrm{C}$, até obtenção de massa constante.

O delineamento estatístico foi inteiramente casualizado, sendo utilizadas três repetições por tratamento para cada genótipo, sendo cada repetição composta por dez embriões e a unidade experimental formada por um tubo de ensaio, contendo um embrião. Os resultados foram submetidos à análise de variância pelo software SAS 9.1.3 e a teste de médias pelo teste " $t$ ".

\section{RESULTADOS E DISCUSSÃO}

As características de crescimento analisadas por regressão indicaram que, na maioria dos cultivares, houve efeito linear significativo para as plântulas submetidas ao déficit hídrico $(\mathrm{P}<0,01$ e $\mathrm{P}<0,05)$ demonstrando-se, desta forma, que os agentes PEG 6000 e manitol causaram estresse nos cultivares testados, sendo significativa a interação entre agente osmótico e genótipo.

Em relação ao comprimento relativo da parte aérea, houve redução expressiva para todos os genótipos com o aumento das concentrações de PEG 6000, sendo o 
genótipo Aliança o mais afetado. No potencial osmótico de -0,60 MPa, seu crescimento relativo já se apresentava inferior a 10\% (Figura 1A). Assim, para a maior concentração testada, - $0,80 \mathrm{MPa}$, a maioria dos genótipos não apresentou desenvolvimento da parte aérea, fator que se deve ao efeito negativo deste agente estressante sobre a germinação das sementes, sendo observado somente a emissão inicial da radícula. Cabe destacar que embora com $\mathrm{R}^{2}$ variando entre 0,86 e 0,94, para os cultivares Aliança, BRS207, Ocepar e BH1146, o modelo linear não explica adequadamente o fenômeno biológico, sendo válido apenas em valores de potencial osmótico superiores a - 0,65 ; $-0,72 ;-0,75$ e - $0,78 \mathrm{MPa}$ respectivamente. Para o manitol, a resposta foi semelhante à observada com PEG 6000, porém em menor intensidade (Figura 1B). Os genótipos menos afetados foram o BRS 207 e BH 1146, reduções de 54,75 e $58,53 \%$, respectivamente, entre o tratamento controle e -0,80 MPa. Por outro lado, os mais afetados estão representados por BR 18 e BRS 208, com reduções de 75,91 e $85,52 \%$, respectivamente.

O comprimento relativo da raiz principal também apresentou comportamento distinto, entre os genótipos frente aos agentes indutores de déficit hídrico (Figura 2). Na presença de PEG 6000, em ordem crescente do efeito estressante, os genótipos foram agrupados em: BH 1146, BRS 264, BRS 210, BRS 207, BR 18, Ocepar 14, BRS 208 e Aliança (Figura 2A), sendo que, para o genótipo BH 1146, a redução no crescimento, entre o tratamento controle e o tratamento mais estressante (-0,80 MPa) foi de 41,02\%; já para o Aliança, cujo estresse foi mais expressivo, a redução foi próxima de $86 \%$. De forma semelhante, para os tratamentos com manitol, os genótipos ficaram ordenados em: Ocepar 14, BH 1146, BRS 210, BR 18, BRS 207 , BRS 264, BRS 208 e Aliança. Porém, em termos percentuais, é possível verificar que o efeito do manitol foi menos intenso que o expresso por PEG 6000, assim como também observado no comprimento relativo da parte aérea. Desta forma, a redução no crescimento do genótipo menos afetado (Ocepar 14) foi de apenas 33,01\%, e, para o genótipo Aliança, embora também tenha sido o mais afetado, foi próximo a 58,90\% (Figura 2B).

Braccini et al. (1996), trabalhando com sementes de soja, verificaram redução na percentagem de germinação, à medida que os potenciais osmóticos das soluções de PEG e manitol tornaram-se mais negativos, e verificaram, ainda, que o PEG foi o agente osmótico que promoveu maior decréscimo na germinação. De acordo com Carvalho \& Nakagawa (2000), o potencial hídrico afeta o alongamento celular e a síntese de parede e para cada espécie existe um valor de potencial hídrico crítico, abaixo do qual a germinação não ocorre (Carvalho, 2005). Para os genótipos de trigo aqui estudados, foi possível observar que, sob potencial osmótico de -0,40 MPa ou mais negati- vos, a redução no crescimento das raízes e da parte aérea das plântulas configurou valores superiores a $50 \%$, variando, no entanto, para cada genótipo.

Machado Neto et al. (2006), estudando o efeito dos agentes osmóticos manitol, $\mathrm{CaCl}_{2}, \mathrm{KCl}$ e $\mathrm{NaCl}$ na germinação e vigor de sementes de feijão, observaram que o manitol foi o agente osmótico que menos afetou o comprimento radicular. Por outro lado, em soja, o potencial osmótico mais negativo induzido com manitol afetou o crescimento do hipocótilo, com decréscimo acentuado até -1,2 MPa e, também das raízes, as quais não apresentaram



\section{Equações:}

Aliança $y=86,80-107,49 x\left(R^{2}=0,78\right) ; B H 1146 y=96,26-51,29 x\left(R^{2}=0,82\right)$ BR18 y=96,98-82,98x $\left(R^{2}=0,80\right)$; BRS207 $y=82,28-65,94 x\left(R^{2}=0,75\right)$ BRS208 y=100,52-93,99x ( $\left.R^{2}=0,90\right) ; B R S 210 y=88,93-65,75 x\left(R^{2}=0,65\right)$ BRS264 $y=101,21-70,61 x\left(R^{2}=0,70\right)$; Ocepar14 y=100,17-87,44x $\left(R^{2}=0,85\right)$

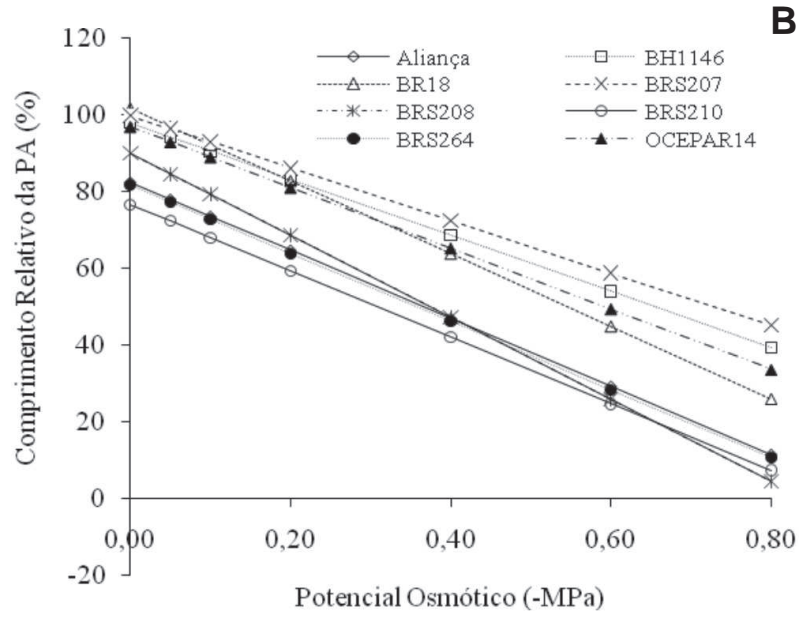

Equações:

Aliança $y=75,11-73,63 x\left(R^{2}=0,67\right) ; B H 1146 y=100,48-51,60 x\left(R^{2}=0,98\right)$ BR18 y=86,30-65,50x ( $\left.R^{2}=0,82\right)$; BRS207 y=86,69-67,76x $\left(R^{2}=0,74\right)$ BRS208 $y=81,44-70,60 x\left(R^{2}=0,80\right)$; BRS210 y=98,06-68,02x $\left(R^{2}=0,95\right)$ BRS264 y=74,73-63,52x $\left(R^{2}=0,97\right)$; Ocepar14 y=90,80-41,24x $\left(R^{2}=0,96\right)$

Figura 1. Comprimento relativo da parte aérea (PA) de plântulas de oito genótipos de trigo submetidos ao estresse hídrico induzido por PEG 6000 (A) e manitol (B).

Rev. Ceres, Viçosa, v. 59, n.2, p. 192-199, mar/abr, 2012 
crescimento a partir do potencial de -0,6 MPa (Machado Neto et al., 2004).

Em conformidade com as respostas observadas para o crescimento das partes aérea e radicular, os agentes indutores de déficit hídrico também afetaram a produção de biomassa dos genótipos de trigo. Para o PEG 6000 (Figura 3A), mais uma vez o genótipo Aliança sofreu maior redução, com massa de matéria fresca total aproximadamente $87 \%$ inferior, no tratamento de maior nível de estresse, em relação ao controle. Ao comparar este genótipo com o BH 1146, cuja redução foi de apenas $44,81 \%$, é possível observar sua maior sensibilidade ao

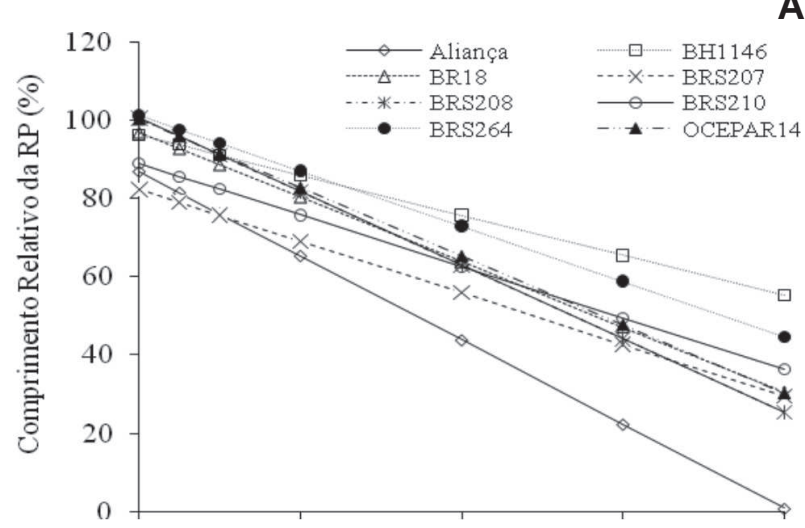

Equações:

Aliança $y=86,67-108,32 x\left(R^{2}=0,85\right)$; BH1146 $y=77,67-56,01 x\left(R^{2}=0,84\right)$ BR18 y=93,56-61,50x $\left(R^{2}=0,93\right)$; BRS207 y=85,40-70,55x $\left(R^{2}=0,83\right)$ BRS208 y=82,53-72,98x $\left(R^{2}=0,81\right)$; BRS210 $y=90,91-67,68 x\left(R^{2}=0,89\right)$ BRS264 y=85,84-74,17x $\left(R^{2}=0,83\right)$; Ocepar14 y=93,73-66,54x $\left(R^{2}=0,87\right)$

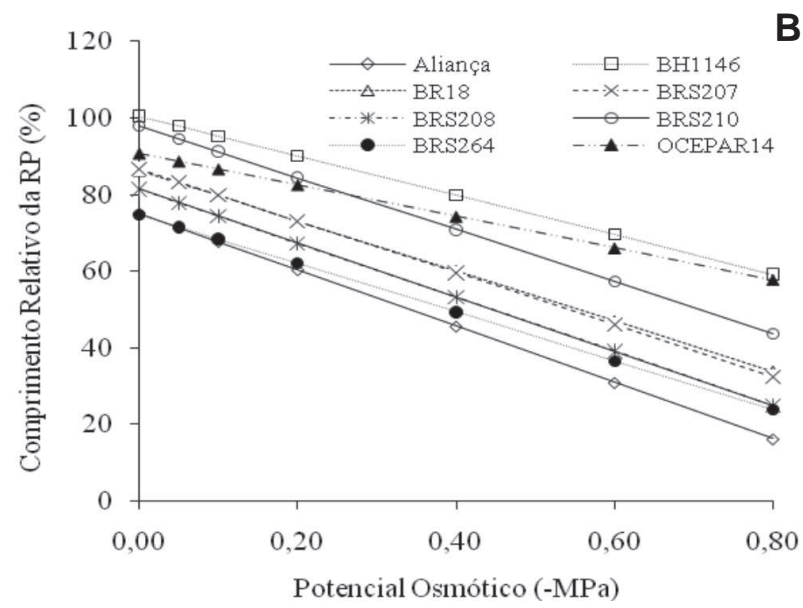

\section{Equações:}

Aliança $y=82,72-71,24 x\left(R^{2}=0,72\right) ; B H 1146 y=90,62-51,63 x\left(R^{2}=0,90\right)$ BR18 y=99,04-57,86x $\left(R^{2}=0,88\right)$; BRS207 y=93,99-43,12x $\left(R^{2}=0,91\right)$ BRS208 y=93,09-72,61x $\left(R^{2}=0,91\right)$; BRS210 y=89,71-45,40x $\left(R^{2}=0,78\right)$ BRS264 y=60,73-62,39x ( $\left.{ }^{2}=0,95\right)$; Ocepar14 y=94,13-40,50x $\left(R^{2}=0,90\right)$

Figura 2. Comprimento relativo da raiz principal (RP) de plântulas de oito genótipos de trigo submetidos ao estresse hídrico induzido por PEG 6000 (A) e manitol (B). déficit hídrico, quando induzido pelo agente estressante PEG 6000. Por outro lado, na presença do manitol (Figura 3B), o efeito em maior intensidade foi observado no genótipo BRS 208, com redução de 58,09\%, seguido, porém, do Aliança, com massa de matéria fresca 57,01\% inferior, sob potencial osmótico de -0,80 MPa. Assim como observado no caso do comprimento radicular (Figura 2B), o menor efeito sobre a produção de biomassa também foi observado no genótipo Ocepar 14, apenas 32,40\% de redução (Figura 3B).

A diminuição na produção de biomassa, tanto da parte aérea como das raízes, está relacionada com a falta de

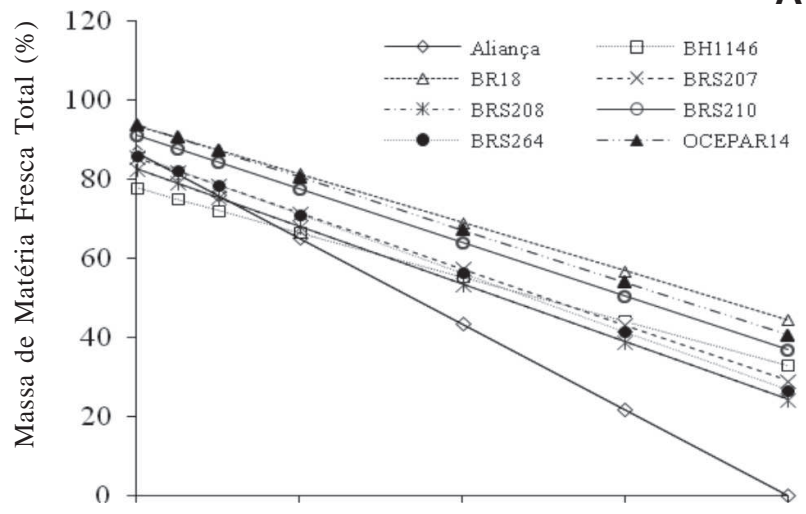

Equações:

Aliança $y=86,67-108,32 x\left(R^{2}=0,85\right) ; B H 1146 y=77,67-56,01 x\left(R^{2}=0,84\right)$ BR18 y=93,56-61,50x $\left(R^{2}=0,93\right)$; BRS207 y=85,40-70,55x $\left(R^{2}=0,83\right)$ BRS208 $y=82,53-72,98 x\left(R^{2}=0,81\right)$; BRS210 $y=90,91-67,68 x\left(R^{2}=0,89\right)$ BRS264 y=85,84-74,17x $\left(R^{2}=0,83\right)$; Ocepar14 y=93,73-66,54x $\left(R^{2}=0,87\right)$



Equações:

Aliança $y=82,72-71,24 x\left(R^{2}=0,72\right) ; B H 1146 y=90,62-51,63 x\left(R^{2}=0,90\right)$ BR18 y=99,04-57,86x $\left(R^{2}=0,88\right)$; BRS207 y=93,99-43,12x $\left(R^{2}=0,91\right)$ BRS208 y=93,09-72,61x $\left(R^{2}=0,91\right)$; BRS210 y=89,71-45,40x $\left(R^{2}=0,78\right)$ BRS264 y=60,73-62,39x $\left(R^{2}=0,95\right)$; Ocepar14 y=94,13-40,50x $\left(R^{2}=0,90\right)$

Figura 3. Produção de massa fresca total de plântulas de oito genótipos de trigo submetidos ao estresse hídrico induzido por PEG 6000 (A) e manitol (B). 
água para o metabolismo, o que reduz a velocidade das reações metabólicas e, consequentemente, diminui o acúmulo de massa de matéria seca (Marur et al., 1994). Segundo estudo de Kerepsi \& Galiba (2000), também com genótipos de trigo, foi observado que, com a aplicação de PEG e $\mathrm{NaCl}$ em volume crescente, houve redução significativa na produção de massa de matéria seca, no conteúdo relativo de água na folha e na perda relativa de água. Estas tendências foram observadas em todos os genótipos estudados, mas sob graus diferentes.

Braga et al. (1999), utilizando o mesmo método de avaliação da disponibilidade hídrica do substrato e seu efeito sobre o potencial das sementes de feijão cv. IAC-Carioca, observaram que, nos potenciais hídricos de -0,4 a -0,6 $\mathrm{MPa}$, houve redução na percentagem de germinação, nas plântulas normais obtidas na primeira contagem do teste de germinação, na velocidade de germinação, no comprimento do hipocótilo e da radícula e na massa de matéria seca das plântulas, bem como, aumento na percentagem de plântulas anormais. Ávila et al. (2007) observaram que, sob níveis mais negativos de potencial osmótico (-1,0 $\mathrm{MPa}$ ) induzido por manitol, o decréscimo na absorção de água pelas sementes causou redução drástica no comprimento do hipocótilo e da raiz principal e na biomassa seca das plântulas, quando comparados com os da testemunha, evidenciando o efeito prejudicial da baixa disponibilidade de água.

Com base nos resultados deste trabalho, comparando-se os dois agentes indutores de déficit hídrico, foi observado que os efeitos negativos sobre o crescimento das plântulas foram mais intensos na presença de PEG 6000 do que na do manitol, independentemente do genótipo e da variável analisada. De maneira geral, a melhor resposta ao estresse foi apresentada pelos genótipos Ocepar 14 e BH 1146, estando em acordo com as informações cedidas pelo Banco Ativo de Germoplasma de Cereais de Inverno da Embrapa Trigo, que os classifica como potencialmente tolerantes à seca. Já para o genótipo Aliança, houve discrepância com as informações cedidas, uma vez que, neste estudo, esse genótipo apresentou alta sensibilidade ao estresse hídrico. Entretanto, como estes resultados foram obtidos em plântulas, sua adaptação a ambientes semiáridos pode estar relacionada com outros fatores de tolerância à seca, tais como: idade da planta, profundidade do sistema radicular, mecanismos de abertura e fechamento de estômatos, características foliares xeromórficas, ajustamento osmótico, intensidade e duração do período de estresse, entre outros.

Além dos efeitos sobre o crescimento das plântulas dos genótipos de trigo oriundas de sementes, os agentes estressantes acima citados e aqui, adicionalmente, a maltose, também tiveram suas respostas avaliadas em plântulas oriundas de embriões imaturos, cultivados em meio de cul- tura macrobatata (Tabelas 1 e 2). Para tanto, os resultados do cultivo dos embriões por um período de 30 dias demonstraram o efeito, não apenas dos agentes indutores de déficit hídrico, mas também da cultura in vitro, per se, sobre o desenvolvimento das plântulas. Dessa forma, sem a presença dos agentes no meio de cultura, o comprimento da parte aérea e o da raiz principal, além das massas de matéria fresca e seca, foram significativamente superiores aos do genótipo BRS 207; porém, para as duas primeiras variáveis, estas características não diferiram das do genótipo BRS 264. Os genótipos BH 1146, BR 18, BRS 208 e BRS 210 apresentaram comportamento intermediário e valores significativamente inferiores de crescimento foram observados para Ocepar 14 e Aliança (Tabela 1).

Para o efeito conjunto dos três agentes indutores de déficit hídrico, PEG 6000, manitol e maltose, as características de crescimento analisadas foram significativamente superiores para os genótipos BH 1146, BRS 207, BRS 208 e BRS 210. Por outro lado, Aliança, Ocepar 14 e BR 18 foram os mais afetados pelo estresse imposto (Tabela 2). O maior comprimento de parte aérea em resposta aos agentes estressantes foi observado para o genótipo BH 1146, com valor de $3,3633 \mathrm{~cm}$, embora não tenha diferido significativamente do observado para BRS 207 e BRS 208. Em contraste, os menores valores foram obtidos para Ocepar $14(0,6511 \mathrm{~cm})$ e BR $18(0,6200 \mathrm{~cm})$, os quais não diferiram do Aliança $(0,8489 \mathrm{~cm})$. Para as raízes, os maiores comprimentos foram observados em BRS $208(0,7189 \mathrm{~cm})$, BRS $210(0,6978 \mathrm{~cm})$ e BH $1146(0,6689 \mathrm{~cm})$, e a maior redução para BR $18(0,1700 \mathrm{~cm})$ e Ocepar $14(0,1611 \mathrm{~cm})$. A massa de matéria fresca total foi superior em BRS $210(0,0217 \mathrm{~g})$, BH $1146(0,0216$ g) e BRS 207 (0,205 g) e os menores incrementos em massa foram observados em Aliança $(0,0056 \mathrm{~g})$ e BR 18 (0,0040 g). Os maiores valores de massa de matéria seca total também foram obtidos com os genótipos BRS 207 (0,0044 g), BH $1146(0,0038$ g) e BRS $210(0,0032$ $\mathrm{g}$ ), sendo que este último não diferiu dos genótipos que apresentaram incremento intermediário. Os genótipos BR 18 e Ocepar 14 apresentaram os menores incrementos, 0,0004 g e 0,0002 g, respectivamente. Para esta variável, valor expressivamente inferior também foi observado para o genótipo Aliança $(0,0009 \mathrm{~g})$, embora não tenha diferido significativamente dos genótipos com produção de massa de matéria seca intermediária.

Estes resultados confirmam a maior tolerância à seca do genótipo de trigo BH 1146, coincidindo com as respostas obtidas na primeira etapa do experimento e com as indicações apresentadas pelo Banco Ativo de Germoplasma da Embrapa Trigo. Por outro lado, Ocepar 14 não apresentou a mesma tendência, porém é importante destacar que este genótipo já apresentou baixo desempenho, quando cultivado em meio de cultura sem a presença dos agentes estressantes, podendo, supostamente, ser tolerante 
Tabela 1. Comprimento médio da parte aérea, raiz principal, massa de matéria fresca e seca de plântulas de oito genótipos de trigo, obtidos a partir de embriões imaturos, cultivados por 30 dias em meio de cultura macrobatata sem o suplemento dos agentes estressantes

\begin{tabular}{lcccc}
\hline \multicolumn{1}{c}{ GENÓTIPOS } & $\begin{array}{c}\text { Comprimento } \\
\text { parte aérea }(\mathbf{c m})\end{array}$ & $\begin{array}{c}\text { Comprimento } \\
\text { raiz principal }(\mathbf{c m})\end{array}$ & $\begin{array}{c}\text { M. de matéria } \\
\text { fresca total }(\mathbf{g})\end{array}$ & $\begin{array}{c}\text { M. de matéria } \\
\text { seca total }(\mathbf{g})\end{array}$ \\
\hline BRS 207 & $20,130 \mathrm{a}^{*}$ & $9,800 \mathrm{a}$ & $0,3060 \mathrm{a}$ & $0,03700 \mathrm{a}$ \\
BRS 264 & $14,770 \mathrm{ab}$ & $6,390 \mathrm{ab}$ & $0,1194 \mathrm{~b}$ & $0,01530 \mathrm{~b}$ \\
BRS 208 & $10,340 \mathrm{~b}$ & $3,280 \mathrm{bc}$ & $0,0680 \mathrm{bc}$ & $0,01000 \mathrm{bcd}$ \\
BR 18 & $9,760 \mathrm{bc}$ & $4,530 \mathrm{bc}$ & $0,0750 \mathrm{bc}$ & $0,01200 \mathrm{bc}$ \\
BRS 210 & $9,270 \mathrm{bc}$ & $3,220 \mathrm{bc}$ & $0,0559 \mathrm{bc}$ & $0,00660 \mathrm{bcd}$ \\
BH 1146 & $7,790 \mathrm{bcd}$ & $3,790 \mathrm{bc}$ & $0,0810 \mathrm{bc}$ & $0,01000 \mathrm{bcd}$ \\
OCEPAR 14 & $3,260 \mathrm{~cd}$ & $1,950 \mathrm{c}$ & $0,0220 \mathrm{c}$ & $0,00300 \mathrm{~cd}$ \\
ALIANÇA & $1,610 \mathrm{~d}$ & $1,290 \mathrm{c}$ & $0,0170 \mathrm{c}$ & $0,00100 \mathrm{~d}$ \\
\hline
\end{tabular}

*Médias seguidas da mesma letra, na coluna, não diferem significativamente pelo teste "t" a 5\% de probabilidade.

Tabela 2. Comprimento médio da parte aérea, raiz principal, massa fresca e seca de plântulas de oito genótipos de trigo, obtidos a partir de embriões imaturos, cultivados por 30 dias em meio de cultura macrobatata, suplementado com três concentrações de PEG 6000 , maltose e manitol

\begin{tabular}{lcccc}
\hline \multicolumn{1}{c}{ GENÓTIPOS } & $\begin{array}{c}\text { Comprimento } \\
\text { parte aérea }(\mathbf{c m})\end{array}$ & $\begin{array}{c}\text { Comprimento } \\
\text { raiz principal }(\mathbf{c m})\end{array}$ & $\begin{array}{c}\text { M. de matéria } \\
\text { fresca total }(\mathbf{g})\end{array}$ & $\begin{array}{c}\text { M. de matéria seca } \\
\text { total }(\mathbf{g})\end{array}$ \\
\hline BRS 207 & $2,5833 \mathrm{ab}^{*}$ & $0,4889 \mathrm{ab}$ & $0,0205 \mathrm{a}$ & $0,0044 \mathrm{a}$ \\
BRS 264 & $1,8844 \mathrm{~b}$ & $0,4744 \mathrm{ab}$ & $0,0108 \mathrm{bc}$ & $0,0025 \mathrm{~b}$ \\
BRS 208 & $2,5544 \mathrm{ab}$ & $0,7189 \mathrm{a}$ & $0,0130 \mathrm{~b}$ & $0,0023 \mathrm{~b}$ \\
BR 18 & $0,6200 \mathrm{c}$ & $0,1700 \mathrm{c}$ & $0,0040 \mathrm{c}$ & $0,0004 \mathrm{c}$ \\
BRS 210 & $2,4578 \mathrm{~b}$ & $0,6978 \mathrm{a}$ & $0,0217 \mathrm{a}$ & $0,0032 \mathrm{ab}$ \\
BH 1146 & $3,3633 \mathrm{a}$ & $0,6689 \mathrm{a}$ & $0,0216 \mathrm{a}$ & $0,0038 \mathrm{a}$ \\
OCEPAR 14 & $0,6511 \mathrm{c}$ & $0,1611 \mathrm{c}$ & $0,0026 \mathrm{~d}$ & $0,0002 \mathrm{c}$ \\
ALIANÇA & $0,8489 \mathrm{bc}$ & $0,2511 \mathrm{bc}$ & $0,0056 \mathrm{c}$ & $0,0009 \mathrm{bc}$ \\
\hline
\end{tabular}

*Médias seguidas da mesma letra, na coluna, não diferem significativamente pelo teste "t" a 5\% de probabilidade.

ao déficit hídrico, mas não ao cultivo in vitro a que foi exposto. Os resultados sugerem que as respostas aos agentes estressantes estão condicionadas também ao meio em que as plântulas são cultivadas, a exemplo do genótipo BR 18, cujo crescimento, avaliado a partir de sementes germinadas em papel umedecido com os agentes estressantes, apresentou comportamento intermediário entre o dos outros genótipos; porém, o desenvolvimento dos embriões imaturos deste genótipo, cultivados em meio macrobatata suplementado com os três agentes, teve desempenho dos mais baixos.

O tipo de agente indutor de estresse também é um fator de variação no desempenho dos genótipos. O polietilenoglicol vem, de fato, sendo utilizado com sucesso em trabalhos de pesquisa, para simular os efeitos do déficit hídrico nas plantas, há mais de 30 anos (Michel \& Kaufmann 1973). Vários autores consideram o PEG 6000 como o soluto mais adequado para a simulação de estresse osmótico em plantas de trigo, uma vez que possui elevado peso molecular; não é tóxico; não penetra nas células e não é eletrolítico (Hasegawa et al., 1984). Em um estudo, comparando o efeito das soluções de PEG e do manitol, observou-se que o teor de água das sementes de alface foi mais baixo quando elas foram mantidas em solução de PEG, apesar de o potencial hídrico de manitol apresentarse mais negativo (Eira, 1988).

Nesse contexto, apesar de o uso de agentes de estresse osmótico para simular condições de déficit hídrico ser uma possibilidade para, antecipadamente, proceder-se à seleção de material genético, agregando maior eficiência e eficácia ao programa de melhoramento para tolerância à seca, para tal há que se evitar o mascaramento de resultados, como esse verificado para manitol e maltose, no experimento conduzido neste estudo. A esse respeito, Frett et $a l .$, (1991) estão entre os autores que discutem o efeito negativo de moléculas de baixo peso molecular sobre sementes, por exemplo, uma vez que podem penetrar nas células e causar toxidez ao organismo.

Para todas as características avaliadas neste experimento, verificou-se que houve diminuição das medidas de crescimento, por causa das concentrações do índice de déficit hídrico. O manitol foi o agente estressante mais tóxico, seguido por maltose e PEG 6000, que foi considerado o agente estressante mais adequado para a seleção dos genótipos, resultado este relevante, em consequência de as concentrações estarem adequadas ao método. Em 
concentrações mais baixas (10\%), o manitol foi extremamente tóxico aos genótipos, não ocorrendo nem crescimento nem diferenciação celular, pois a sua concentração inicial já estava alta. O mesmo foi observado para a maltose, que, em nível intermediário (20\%), também, praticamente paralisou o crescimento das plântulas.

\section{CONCLUSÕES}

O déficit hídrico induzido por PEG 6000 e manitol causa decréscimo no crescimento dos genótipos de trigo, porém em proporções distintas. Este comportamento permite a identificação precoce de genótipos potencialmente tolerantes ao déficit hídrico, sendo BH 1146 e Ocepar caracterizados pelo melhor desempenho ao estresse imposto e o genótipo Aliança é o que apresenta a maior sensibilidade. Porém, as respostas aos agentes estressantes são condicionadas ao meio em que as plântulas são cultivadas, havendo divergências com as observações de campo, fornecidas pelo Banco Ativo de Germoplasma da Embrapa Trigo.

\section{REFERÊNCIAS}

Abitrigo (2010) Associação Brasileira da Indústria do Trigo. História do trigo. O papel do trigo na evolução da humanidade. A triticultura brasileira. Disponível em: http://www.abitrigo.com.br/ historia_do_trigo2a.asp Acessado em: 22 de maio de 2010.

Ávila MR, Braccini A de L, Scapim CA, Fagliari JR \& dos Santos JL (2007) Influência do estresse hídrico simulado com manitol na germinação de sementes e crescimento de plântulas de canola. Revista Brasileira de Sementes, 29:98-106.

Barros CS \& Rossetto CAV (2009) Teste de germinação sob condições de restrição hídrica para avaliar o vigor de sementes de girassol. Ciência Rural, 39:2621-2624.

Braccini AL, Ruiz HA, Braccini MCL \& Reis MS (1996) Germinação e vigor de sementes de soja sob estresse hídrico induzido por soluções de cloreto de sódio, manitol e polietileno glicol. Revista Brasileira de Sementes, 18:10-16.

Braga LF, Sousa MP, Braga JF \& Sá ME (1999) Efeito da disponibilidade hídrica no substrato na qualidade fisiológica de semente de feijão. Revista Brasileira de Sementes, 21:95-102.

Carvalho N \& Nakagawa J (2000) Sementes: Ciência, tecnologia e produção. $4^{\mathrm{a}}$ ed., Jaboticabal, FUNEP, 588p.

Carvalho CJR (2005) Respostas de plantas de Schizolobium amazonicum [S. parahyba var. amazonicum] e Schizolobium parahyba [Schizolobium parahybum] à deficiência hídrica. Revista Árvore, 29:907-914.

Chuang CC, Yang TW \& Chia H (1981) A set of potato media for wheat anther culture. In: Symposium on Plant Tissue Culture, 1978, Peking. Boston, Proceedings, Pitman Advanced Publishing Program. p. 51-56.

CONAB (2010) Companhia Nacional de Abastecimento. Brasil: Oferta e demanda de produtos selecionados (Mil toneladas). Disponível em: http://www.cnpt.embrapa.br/pesquisa/economia/ FdemandaBR.htm Acessado em: 28 de maio de 2010.

Denadai IAM \& Klar AE (1995) Resistência à seca em quatro cultivares de trigo: parâmetros fisiológicos. Scientia Agricola, 52:274-281.
Frett JJ, Pill WG \& Morneau DC (1991) A comparison of priming agents for tomato and asparagus seeds. HortScience, 26:11581158 .

Fumis TF \& Pedras JF (2002) Variação nos níveis de prolina, diamina e poliaminas em cultivares de trigo submetidas a déficits hídricos. Pesquisa Agropecuária Brasileira, 37:449-453.

Göpfert H, Rossetti LA \& Souza J (1993) Eventos generalizados e securidade agrícola. Brasília, IPEA, Ministério do Planejamento, $78 \mathrm{p}$.

Kerepsi I \& Galiba G (2000) Osmotic and salt stress-induced alteration in soluble carbohydrate content in wheat seedlings. Crop Science, 40:482-487.

Hasegawa PM, Bressan RA, Handa S \& Handa AK (1984) Cellular mechanisms of tolerance to water stress. HortScience, 19:371377.

Machado Neto NB, Custódio CC, Costa PR \& Doná FL (2006) Deficiência hídrica induzida por diferentes agentes osmóticos na germinação e vigor de sementes de feijão. Revista Brasileira de Sementes, 28:142-148.

Machado Neto NB, Saturnino SM, Bomfim DC \& Custódio CC (2004) Water stress induced by mannitol and sodium chloride in soybean cultivars. Brazilian Archives of Biology and Technology, 47:521-529.

Marur CJ, Sodek L \& Magalhães AC (1994) Free aminoacids in leaves of cotton plants under water deficit. Revista Brasileira de Fisiologia Vegetal, 6:103-108.

Meneses CHSG, Bruno RLA, Fernandes PD, Pereira WE, Lima LHGM, Lima MMA \& Vidal MS (2011) Germination of cotton cultivar seeds under water stress induced by polyethyleneglycol6000. Scientia Agricola, 68:131-138.

Michel BE \& Kaufmann MR (1973) The osmotic potential of polyethylene glycol 6000. Plant Physiology, 51:914-916.

Nogueira RJMC, Moraes JAPV \& Burity HA (2001) Alterações na resistência à difusão de vapor das folhas e relações hídricas em aceroleira submetidas a déficit de água. Revista Brasileira de Fisiologia Vegetal, 13:75-87.

Pirdashti H, Tahmasebi ZS, Nematzadeh GH \& Ismail A (2003) Effect of water stress on seed germination and seedling growth of rice (Oryza sativa L.) genotypes. Pakistan Journal of Agronomy, 2:217-222.

Schuab SRP, Braccini AL, Scapim CA, França-Neto JB, Meschede DK \& Ávila MR (2007) Germination test under water stress to evaluate soybean seed vigour. Seed Science \& Technology, 35:187-199.

Silva JB da, Rodrigues TJD \& Vieira RD (2006) Desempenho de sementes de soja submetida a diferentes potenciais osmóticos em polietilenoglicol. Ciência Rural, 23:1634-1637.

Tonin GA, Carvalho NM, Kronka SN \& Ferraudo AS (2000) Culture systems, velvet bean and mineral fertilization influence on maize seeds physiological quality. Revista Brasileira de Sementes, 22:276-279.

Vazquez GH (1995) Condicionamento fisiológico de sementes de soja: efeitos sobre germinação, vigor e potencial de armazenamento. Dissertação de Mestrado. Escola Superior de Agricultura "Luiz de Queiroz", Piracicaba, 138p. 